Dmytro Dmytrevskyi, $\mathrm{PhD}$ in Engineering Sciences, Associate Professor ORCID: 0000-0003-1330-7514

ResearcherID: G-2406-2016

Vitalii Chervonyi, $\mathrm{PhD}$ in Engineering Sciences, Associate Professor ORCID: 0000-0002-9085-2260, ResearcherID: AAG-6209-2020

Dmytro Horielkov, $\mathrm{PhD}$ in Engineering Sciences, Associate Professor ORCID: 0000-0002-9315-9322

ResearcherID: AAI-1050-2020

Kharkiv State University of Food Technology and Trade, Kharkiv, Ukraine

\title{
DETERMINATION OF RATIONAL PARAMETERS OF THE PROCESS OF HEAT TREATMENT DURING THE PREPARATION OF APPLE PUREE
}

The necessity of improving the equipment for making apple puree is proved. Dependences of influence of heat treatment parameters on the structural and mechanical properties of raw materials were obtained. The rational parameters of carrying out the process of heat treatment of fruit raw materials are determined.

Keywords: apple puree, heat treatment, penetration, wiping, grinding.

Relevance of the research topic. Fruit and vegetable industry is an important sector of the agro-industrial complex. In recent years, special attention has been paid to improving production technology, introduction of more productive equipment, expansion the range of processed raw materials. The production of various highquality products of diet food, food concentrates, fresh frozen fruits and vegetables, semi-finished products, high-canned foods is developing rapidly [1].

The processing of fruits and vegetables is a rather laborious, requires storage and recycling, the availability of special workshops and staff. The use of high availability raw materials has a number of significant advantages: first, food businesses can obtain a standardized safe product of stable quality; secondly, it is possible to reduce the storage area for raw vegetables [2]. 
Formulation of the problem. Investigation of the influence of physicochemical and mechanical processes occurring in fruits and vegetables during heat treatment in the process of preparation of semi-finished products in order to obtain rational parameters of the process is an urgent task.

Analysis of recent researches and publications. The developed combined method of processing consists of the process of thermal treatment of the fruit with steam and their mechanical grinding [3].

The primary task in conducting studies of the combined process of fruit processing was to determine the rational duration of heat treatment. Heat treatment of apples is one of the main stages in the process of obtaining apple puree. Raw materials are subjected to heat treatment, which is carried out in water vapor, in hot water, aqueous solutions of acid, alkali, salt, hot animal or vegetable fats, and by contact with the surface of heating, before cutting, grinding and wiping [4].

To ensure the desired depth of heat treatment, it is necessary to set a rational duration for the treatment of apples with steam or water.

During the research, the dependence of the depth of heat treatment of apples on the duration of treatment with water, steam, pressure was established. Apples blanching were carried out in boiling water for $70 \ldots 90 \mathrm{~min}$ at atmospheric pressure and hot steam at $115 \ldots 125^{\circ} \mathrm{C}$ for $30 \mathrm{~min}$.

Presenting main material. The purpose of the research was to determine the rational duration of heat treatment of apples during the production of apple puree. Apples blanching were carried out in boiling water for $70 \ldots 90 \mathrm{~min}$ at atmospheric pressure and hot steam at $115 \ldots 125^{\circ} \mathrm{C}$ for $30 \mathrm{~min}$.

To objectively evaluate the degree of softening of the structure of apples during heat treatment, an indicator of the specific effort of penetration was introduced. This indicator characterizes the changes in the mechanical strength of the raw material structure during processing and allows judging its readiness for further technological stage (grinding).

The process of changing the mechanical strength of apple tissue can be divided into two periods. The first period is characterized by a relatively intense decrease in the mechanical strength of the fabric until it is ready for further technological stage. For apples treated with hot water and hot steam, this period lasted for 70 and 20 minutes, while the strength of the fabric decreased by 9.5 times.

The second period is characterized by a sharp slowdown in the rate of reduction of the mechanical strength of the fabric after its softening to the degree of readiness for further technological stage. For apples, the strength of the fabric during the period of heat treatment in hot water for 70-90 minutes and steam for 20-35 minutes decreased only 1.5 times.

Experimentally established the required strength of plant tissue for further processing on wiping machines, where the specific penetration force was equal to $70-100 \mathrm{~N} / \mathrm{m}^{2}$. 
According to the experimental data, it can be concluded that the smallest loss of mass fraction of solids occurs during the heat treatment of the apple with a sharp steam. Therefore, in the preparation of apples to the next technological stage, it is rational to use a method of heat treatment with sharp steam for 20-25 minutes.

Excessive steam pressure and treatment temperature were selected as the main factors. The initial parameter was the specific penetration force.

Experiments were conducted on different varieties of apples with different solids content, which are shown in the Fig. 1.

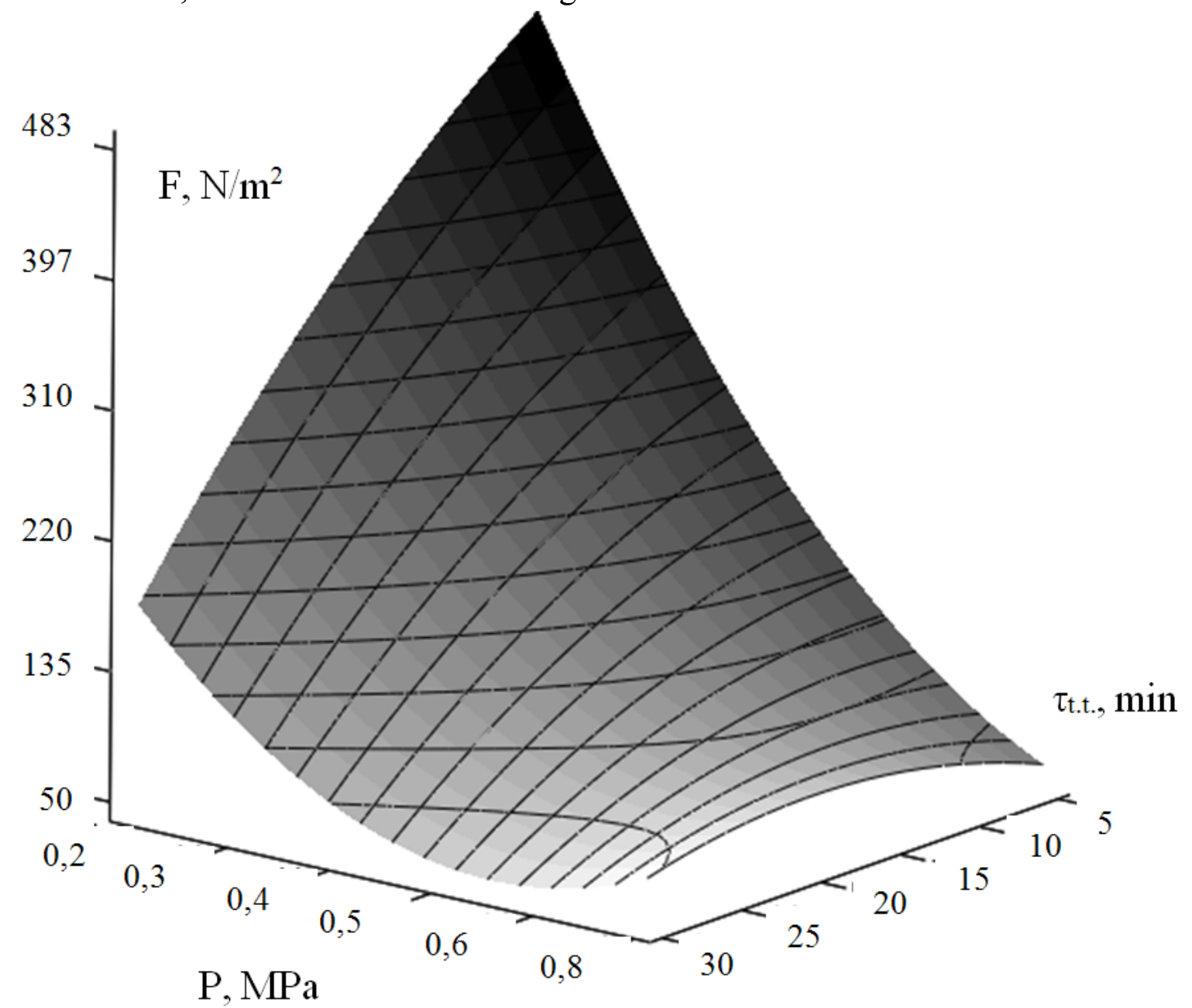

Figure 1. The dependence of the specific penetration force of apples on the excess pressure of steam P, MPa and the duration of thermal treatment with sharp steam $\tau_{t . t .}$ min

A general technological requirement for puree products obtained after grinding is that the mashed potatoes should be a homogeneous mass, the size of the individual particles of which should not exceed $0.5 \ldots 2 \mathrm{~mm}$ (depending on the type of grinding machine).

The grinding of raw materials is carried out to give it a certain shape and facilitate further processes (wiping, homogenization, packaging) upon receipt of puree products. 
The Fig. 2 shows the graphical dependence of the indentation depth of the indenter (knife) on the specific cutting force at different apple varieties and the time of heat treatment (blanching). With increasing blanching time, the value of the specific cutting force decreases.

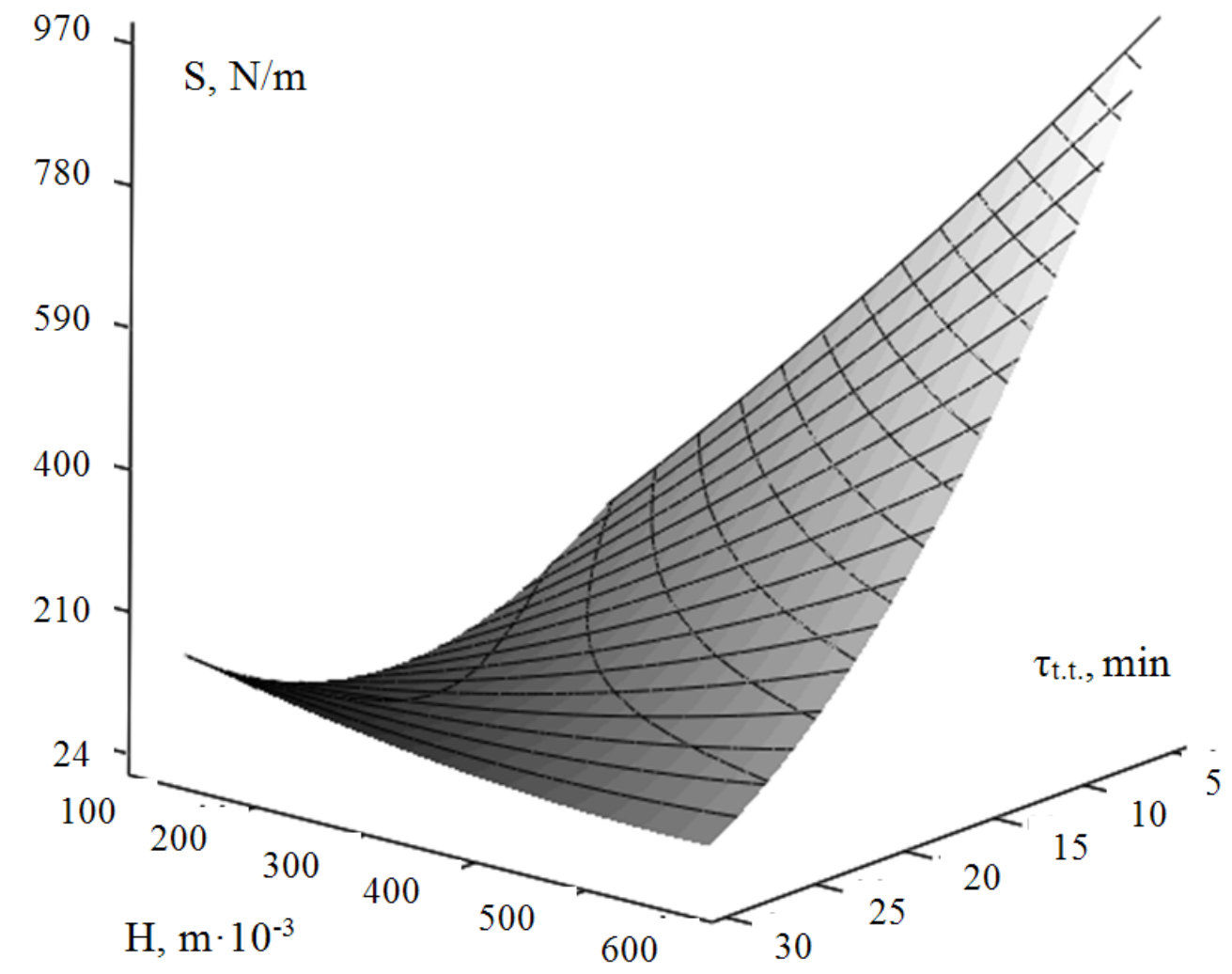

Figure 2. Dependence of the specific effort of cutting apples on the immersion depth of the indenter (knife) $\mathrm{H}, \mathrm{m} 10^{-3}$ and the duration of heat treatment of sharp steam $\tau_{t . t .}$ min

The mechanical strength of the plant tissue in the process of heat treatment is reduced, resulting in the fruits soften as the connections between the cells weaken. The cell shells are loosened, but integrity remains, and destruction of the median plates connecting adjacent cells occurs to a greater extent. As a result, there is a significant reduction in the resistance of the fabric to mechanical influences (cutting, wiping). The tissue cells are easily separated from each other.

The weakening of the connections between cells in the process of heat treatment of the fruit is associated with changes in carbohydrates of the cell walls, mainly protopectin. The product is then wiped through a sieve with a mesh size of $0.5 \mathrm{~mm}$, resulting in the pulp is ground to a homogeneous state.

According to experimental data, due to the use of heat treatment (blanching and wiping) puree is obtained high quality. It is known that the mechanical properties of products play an important role in their production and consumption, as well as characterizing the strength of the mechanical connections acting between the individual 
molecules and their links that are part of the structure. Therefore, the characterization of the structural and mechanical properties of food and mass is one of the most important and objective indicators of their technological properties.

The purity of the puree has a significant effect on the quality of the concentrated paste. With increasing the viscosity during concentration, the movement of the product on the machine elements and apparatus is complicated, the moisture is removed more slowly, thus increasing the concentration time. The visco-plastic properties of fruit and vegetable puree are determined by the content of pectic substances and their condition (protopectin, soluble pectin, pectin of intercellular substance). The high content of pectic substances act as thickeners, the low content as electrolytes and under certain conditions is separated from the liquid phase of the colloidal system. Protopectin cell walls do not have the properties of a thickener and does not affect the viscosity of fruit and vegetable purees. Thus, with the same content of pectin substances in raw materials, the viscosity of fruit and vegetable puree depends on the ratio of the forms of pectin substances in it.

Experiments have also been carried out as the effective viscosity of apple puree depends on the temperature and duration of heat treatment. The experimental data are presented in the Fig. 3.

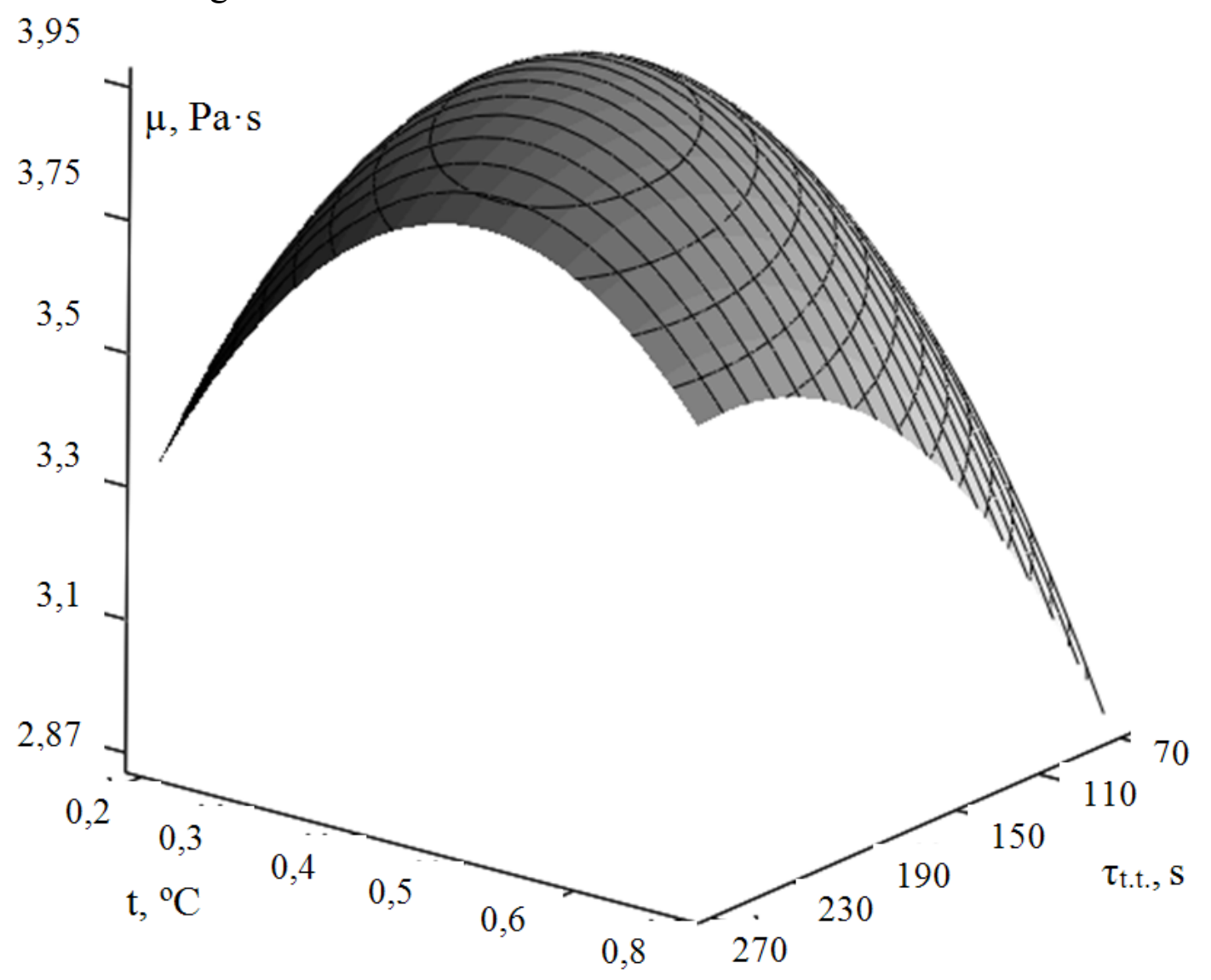

Figure 3. Dependence of effective viscosity $\mu$, Pa s of apple puree on temperature $t,{ }^{\circ} \mathrm{C}$ and duration of heat treatment $\tau_{\text {t.t. }} s$ 
As a result of the performed researches, the most rational parameters for obtaining concentrated pastes with a mass fraction of solids $40 \ldots 60 \%$ were established: the pressure of the heating steam is $0.3 \ldots 0.4 \mathrm{MPa}$; residence time $200 \ldots 260 \mathrm{sec}$. The short residence time of the puree in the evaporator allows obtaining products with the maximum preservation of all useful substances contained in the feedstock.

Conclusions. Therefore, the dependence of the specific force of penetration of apples on excess steam pressure and the duration of heat treatment with hot steam for various varieties of apples is obtained. It has been established that different sorts of fruits and shelf life affect the depth of heat treatment of the surface layer of apples. The depth of heat treatment of apples during blanching increases with increasing pressure.

\section{REFERENCES}

1. Caldwell, E., Kobayashi, M., Dubow W., Wytinck, S. (2008). Perceived access to fruits and vegetables associated with increased consumption. Public Health Nutrition. 6, 10, 1743-1750. doi: 10. 1017/S1368980008004308.

2. Lin, D., Zhao, Y. (2007). Innovations in the development and application of edible coatings for fresh and minimally processed fruits and vegetables. Comprehensive Reviews in Food Science and Food Safety. 6, 3, 60-75. doi:10. 1111/j. 1541-4337. 2007. 00018. x.

3. Pereira, R., Vicente, A. (2009). Environmental impact of novel thermal and non-thermal technologies in food processing. Food Research International. 43, 7, 1936-1943.

4. Siti Mazli, M., Nur Aliaa, A., Nor Hidayati, H., Intan Shaidatul, M., Wan Zuha, W. (2010). Design and Development of an Apparatus for Grating and Peeling Fruits and Vegetables. American Journal of Food Technology. 5, 6. 385-393. 